\title{
Synthesis and Evaluation of a Comb-Like Emulsifier with High Temperature Tolerance for Oil-Based Drilling Fluid
}

\author{
Deng Zhengqiang, Jiang Guancheng, He Yinbo, Huang Xianbing, and Wu Li
}

\begin{abstract}
This paper investigated a comb-like emulsifier based on amines, fatty acid and maleic anhydride. The emulsion properties and character of the emulsifier were studied by FT-IR. Meanwhile the emulsification properties of the prepared emulsion were evaluated, in terms of separation stability, electrical stability, emulsion stability and thermal stability. Then the resistance properties of synthesized emulsifier to salinity, calcium and water were studied. The results indicated that the structure of comb-like emulsifier was confirmed by FTIR analysis. Optimization of synthesis condition investigations demonstrated that reaction temperature was fixed at $165{ }^{\circ} \mathrm{C}$ and reaction time was fixed at $16 \mathrm{~h}$. For the high-temperature resistance of comb-like emulsifier behaviors, the emulsion-breakage voltage of comb-like emulsifier achieved $821 \mathrm{~V}$ subsequent to rolled at $220^{\circ} \mathrm{C}$ for $16 \mathrm{~h}$, while the EZ-MUL surfactant was $353 \mathrm{~V}$ in the same condition. Overall, the oil-based drilling fluid prepared by the synthesized emulsifier, with excellent resistance of calcium chloride and water properties, was superior to EZ-MUL surfactant as the primary emulsifier. Besides the oil-based drilling fluid, which prepared by the comb-like emulsifier, has excellent rheological and filtration properties under complex conditions. The successful combination of high temperature resistance and emulsion stability makes the comb-like emulsifier potentially applicable in deep well, ultra-deep well and unconventional hydrocarbon resources exploration.
\end{abstract}

Index Terms-Comb-like emulsifier, high temperature tolerance, drilling fluid, electrical stability.

\section{INTRODUCTION}

Conventional oil and gas resources decrease gradually, so the exploration and development of petroleum begin to drill deep well with a higher request for high-temperature resistance of drilling fluid [1]-[6]. Thermal and inhibitive stability is a critical issue on drilling progress and troubled the drilling fluid engineers and experts all the time especially in the high angle wells, HTHP wells and extended reach wells [7]. $75 \%$ of the all footage drilled and $90 \%$ of the pipe-sticking problems caused by the shale formation. The oil-based drilling fluids or synthetic-based drilling fluids become characterized by high temperature-tolerance performance and excellent lubrication and inhibitory for shale hydration expansion and an enhanced rate of penetration [8]-[10]. As a consequence, oil-based drilling fluids are

Manuscript received September 30, 2016; revised January 28, 2017.

D. Zhengqiang, H. Yinbo, H. Xianbing, and J. Guancheng are with the Petroleum Engineering Department, CUP University, Beijing, China (e-mail: 492838404@qq.com, 634640236@qq.com, 344925897@qq.com, 15010025286@126.com).

W. Li is with Geological Engineering, Zhonghaiwobang Energy Corporation, Jiuxianqiao, Beijing China (e-mail: 545083127@qq.com). widely employed as the preferred choice of mud.

OBM have similar structure, but instead of water, it is constituted by an inverted emulsion of water-in-oil [11]. Water-in-oil emulsions are commonly employed as oil drilling fluids during drilling operations, therefore preventing emulsion breakage is imperative to maintain its viability and safety [12]. Usually in such scenarios the performance of WBM is not satisfactory and OBM must be employed. OBM are known as less sensitive to variations of rheology, density and other chemical physical properties [13]. However, the increase in strict environmental regulations limits the use of diesel based muds as these muds are toxic and disposal of cuttings into the environment is a major issue faced by the drilling industries. To overcome this issue, an attempt has been made to develop oil-in-water emulsion mud system using Jatropha oil [14].

The mechanism of the comb-like emulsifier with high-temperature resistance is shown in Fig. 1. The comb-like become characterized by multi-hydrophilic and multi-hydrophobic group, so it has lower interfacial tension in water-in-oil emulsion. Furthermore, with a character of high-temperature resistance of hydrophilic and hydrophobic group for comb-like emulsifier, culminating in the stable properties of emulsion stability under complex conditions.

In the present work, our group synthesized condensation polymer based on fatty acid/amines/ maleic anhydride polymer and controlled emulsion stability by polymerization condition. It be used as high-temperature resistance emulsifier agent to emulsify water and oil in oil-based drilling fluid. The emulsion properties of condensation polymer were characterized by separation stability tests and electric stability tests.

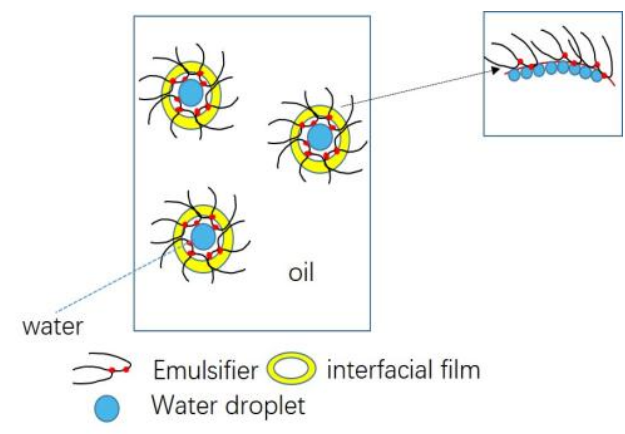

Fig. 1. Scheme of the emulsion mechanism of comb-like emulsifier.

\section{EXPERIMENTAL SECTION}

\section{A. Materials}

The amines and fatty acid were commercial products from Zhengzhou Alfa chemical company, with a purity of $>98 \%$. Maleic anhydride and P-toluene sulfonic acid were purchased 
from Shanghai Aladdin Bio-chemistry Technology limited company, with the purity were analytically pure. Mineral oil, which was industry grade, was purchased form Sinopec Maoming chemical company. Calcium chloride and other reagents were purchased from domestic reagent company. All the reagents were not purification further.

\section{B. Methods}

Synthesis of the comb-like emulsifier. The comb-like emulsifier with high-temperature tolerance was synthesized by condensation neutralization reaction and Diels-Alder addition reaction under the condition of catalyst. Amines(20.4g) was poured into three-necked round-bottomed flask. Then fatty acid(28.2g) was added into flask and oil-water separator was installed and stirred. P-toluene sulfonic acid was poured into flask and increased the temperature to $140^{\circ} \mathrm{C}$. Kept in $140^{\circ} \mathrm{C}$ for $5 \mathrm{~min}$ and increased the temperature to $150^{\circ} \mathrm{C}$. Kept in $150{ }^{\circ} \mathrm{C}$ for $5 \mathrm{~min}$ and increased the temperature to $165^{\circ} \mathrm{C}$. Kept in $165^{\circ} \mathrm{C}$ for $12 \mathrm{~h}$. Calculating the volume of water generated from the reaction. Then cooling the temperature to $60^{\circ} \mathrm{C}$ and maleic anhydride $(9.8 \mathrm{~g})$ was added into the flask and increased the temperature to $85^{\circ} \mathrm{C}$ and the reaction kept for $12 \mathrm{~h}$. The product was cooled at room temperature. Then the product was purified by ethanol under Rotary evaporator. The resulting product was poured into storage containers.

Preparation of emulsion. The brine was made of deionized water and calcium chloride at a concentration of $30 \%$. The oil-based fluid was made of brine and mineral oil with a ratio of oil to water $9: 1$. The emulsifier was added at concentration of $2 \mathrm{wt} \%$ to the mineral oil and stirring for $20 \mathrm{~min}$ at high speed of $5000 \mathrm{rpm}$ and then the brine was added to the solution and stirring for $1 \mathrm{~h}$ at high speed of 10,000 rpm.

Preparation of oil-based drilling fluid. The emulsions with a ratio of oil to water 9:1 were prepared, and then the auxiliary treatment agents were added successively, such as $2 \mathrm{wt} \%$ of the viscosifier, $4 \mathrm{wt} \%$ wetting agent, $1.5 \mathrm{wt} \%$ loss control agent and $3 \mathrm{wt} \% \mathrm{CaO}$, and then $200 \mathrm{wt} \%$ to $400 \mathrm{wt} \%$ barite were added respectively as OBM at four kinds of density and stirring for $1 \mathrm{~h}$ at high speed of 10,000 rpm.

Emulsion stability tests. Emulsion electrical stability was measured according to American Petroleum Institute (API) specifications and Chinese GB/T 16782-1997. The breakage voltage of emulsion stability was measured by Fann23D (American FANN company). Fann23D electrical stability tester (FANN Instrument Company, USA) can measure the stability of the emulsion. The electrode was placed in the test solution, and then the emulsion breakage voltage value could be read out from the device, and then repeated 5 times for the average.

Emulsion separation stability. Demixing phenomena, such as sedimentation, flotation or consolidation were directly measured by the Multi-Wavelength Separation Analyser LUMireader PSA. The sample cell was illuminated by a multicolor light source(I0), including one near infrared wavelength. Behind the sample cell the transmitting light I was detected using a CCD-line (number of elements and pitch distance see Fig. 2). Transmission was converted into extinction by $\ln \left(\mathrm{I} / \mathrm{I}_{0}\right)$.
Anti-temperature property tests. Aging experiments of oil-based fluid were carried out in a GW300-type frequency conversion rolling oven (Qingdao Jiaonan Tong Chun Machinery Plant, China) through hot rolling at appointed temperature $\left(120^{\circ} \mathrm{C}, 150^{\circ} \mathrm{C}, 180^{\circ} \mathrm{C}, 200^{\circ} \mathrm{C}, 220^{\circ} \mathrm{C}\right)$. Emulsion breakage voltage was measured before and after the thermal aging experiments.

Filtration property tests. Filtration property tests were measured according to American Petroleum Institute(API) and Chinese GB/T 16782-1997. The high temperature high pressure(HTHP) filtrate volume of the oil-based drilling fluid was determined with GGS42 HTHP filtration apparatus (Qingdao Tong Chun Petroleum Machinery Corporation, China). A volume of oil-based drilling fluid was load on the filter press equipped with a filter paper and fixed pressure in 3.5MPa. Over time, filter cake is formed on the filter paper and the filtration volume is double of fluids volume produced by the apparatus in 30 minutes.

FT-IR tests. The comb-like emulsifier with purification reduced pressure distillation with acetone were recorded by acetone were recorded by Magna-IR560 spectrometer with the resolution $4 \mathrm{~cm}^{-1}$ and the wavenumber range $4000-400 \mathrm{~cm}^{-1}$ (Nicolet, USA).
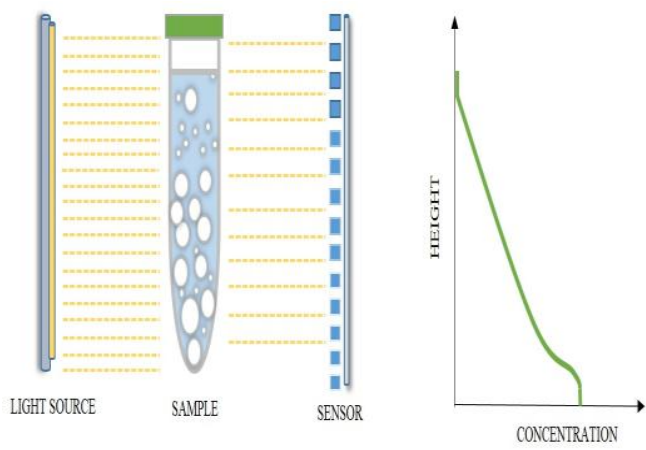

Fig. 2. Measurement principles of STEP-Technology.

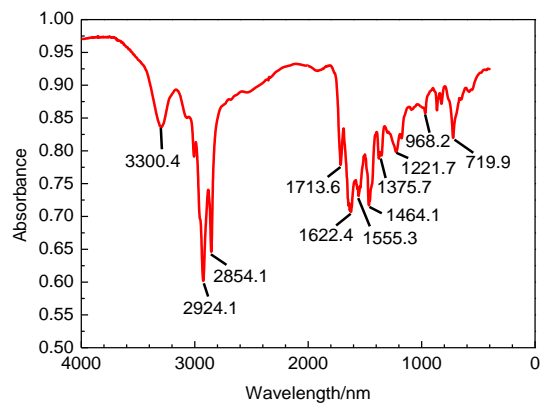

Fig. 3. FT-IR spectra of aliphatic amine/oleic acid/anhydride comb-like emulsifier.

\section{RESULTS AND DISCUSSION}

\section{A. Characterization}

An amount of comb-like emulsifier exist in emulsion. To emulsify water and oil, it is requirement to obtain an emulsifier with high-temperature resistance. Fig. 3 shows FT-IR spectra of comb-like emulsifier under the best optimum synthesis condition. $3304 \mathrm{~cm}^{-1}$ was N-H stretching band. $2854 \mathrm{~cm}^{-1}$ was $\mathrm{C}-\mathrm{H}$ stretching band.1713.6 $\mathrm{cm}^{-1}$ was 
$\mathrm{C}=\mathrm{O}$ stretching band $1555.3 \mathrm{~cm}^{-1}$ and was $\mathrm{C}-\mathrm{N}$ stretching band.1464.1 $\mathrm{cm}^{-1}$ was $\mathrm{C}-\mathrm{H}$ stretching band $1622.4 \mathrm{~cm}^{-1}$ was $\mathrm{C}=\mathrm{C}$ stretching band. $1221.7 \mathrm{~cm}^{-1}$ was $\mathrm{C}-\mathrm{O}$ stretching band. The results exhibited that the condensation polymer emulsifier was aliphatic amine/oleic acid/anhydride comb-like emulsifier.

\section{B. Optimization of Synthesis Condition}

Comb-like emulsifier was synthesized at fixed rate of monomers and initiators, and changed reaction temperature and reaction time. The comb-like emulsifier was synthesized by condensation polymerization. Fig. 4 indicates the changes of filtration volume and emulsion-breakage voltage with reaction temperature. Emulsion-breakage voltage increased with reaction temperature, but emulsion-breakage voltage increased slightly over $165{ }^{\circ} \mathrm{C}$. Filtration volumes were declined then climbed up and up to lowest value at $165{ }^{\circ} \mathrm{C}$. Emulsion-breakage voltage subsequent to emulsifier was low at lower reaction temperature, indicating the yield of emulsifier was too low due to large filtration volume. Integrated into account, reaction temperature was fixed at $165^{\circ} \mathrm{C}$. Fig. 4 and Fig. 5 show change of filtration volumes and emulsion-breakage voltage with reaction time. Emulsion-breakage voltage was almost stable and was kept about $880 \mathrm{~V}$. The range of filtration volumes were from $4.0 \mathrm{~mL}$ to $8.8 \mathrm{~mL}$, showing excellent fluid loss agent performance. Taking into consideration various factors, reaction time was fixed at $16 \mathrm{~h}$. Comb-like emulsifier was synthesized at optimization reaction condition.

\section{Property Evaluations}

As presented in Fig. 6 and Fig. 7 comb-like emulsifier dramatically increased emulsion-breakage voltage of emulsion fluids prepared by it and filtration volumes reduced with the addition of emulsifier. It further proved that the comb-like emulsifier effectively promoted stability by reducing the interfacial tension between water and oil and has excellent emulsifying as well as wetting ability. The property was according to convention emulsifier agent. EZ-MUL was a kind of anionic surfactant which was widely applied in oil field as emulsifier agent. But better high-temperature resistance of comb-like emulsifier promoted their application in extraordinarily high temperature and other complex condition (Fig. 8 and Fig. 9). Emulsion-breakage voltage of EZ-MUL surfactant was $353 \mathrm{~V}$ subsequent to rolled at $220^{\circ} \mathrm{C}$ for $16 \mathrm{~h}$, and it was approximately one third than at room temperature. Emulsion-breakage voltage of EZ-MUL reduced quickly over $220^{\circ} \mathrm{C}$, indicating that the drop of emulsifying controllability of EZ-MUL over $220{ }^{\circ} \mathrm{C}$. Compared with EZ-MUL, the addition of comb-like emulsifier resulted in higher emulsion-breakage voltage and lower filtration volume. Emulsion-breakage voltage of comb-like emulsifier achieved $821 \mathrm{~V}$ and filtration volume was only $4.2 \mathrm{~mL}$ subsequent to rolled at $220^{\circ} \mathrm{C}$ for $16 \mathrm{~h}$. The experiment results shown that the property of resistance-temperature of comb-like emulsifier was superior to EZ-MUL. As presented in Fig. 10 and Fig. 11. Filtration volumes of comb-like emulsifier and EZ-MUL were stable in calcium chloride concentration from 0 to $5 \mathrm{wt} \%$. Filtration volume of EZ-MUL was inferior to comb-like emulsifier, but the difference was nearly small. Anti- calcium chloride property was considered as equally. Resistance-water property was also investigated as presented in Fig. 12, Fig. 13 and Fig. 14. Emulsion-breakage voltage as well as apparent viscosity of comb-like emulsifier and EZ-MUL were unstable in water concentration from 0 to $25 \mathrm{wt} \%$. Apparent viscosity of EZ-MUL was up to $82 \mathrm{mPa} \cdot \mathrm{s}$ subsequent to $25 \mathrm{wt} \%$ water concentration contaminated, and it was approximately 2 times prior to invading of water. Meanwhile, emulsion-breakage voltage of EZ-MUL reduced more significantly than comb-like emulsifier subsequent to $25 \mathrm{wt} \%$ water concentration contaminated, and it was only 113V. Separation stability of comb-like emulsifier also investigated as presented in Fig. 15 and Fig. 16. Transmission of emulsion prepared by comb-like emulsifier and EZ-MUL with the oil-water ratio of 80:20 were stable in different position. The results exhibited that the property of separation stability of comb-like emulsifier and EZ-MUL was equally. Resistance-calcium chloride property was considered as equally as well. Separation stability property was equally, but resistance-high temperature and resistance-water properties of comb-like emulsifier was superior to EZ-MUL, showing comb-like emulsifier can replace EZ-MUL as emulsifier agent in oil field.

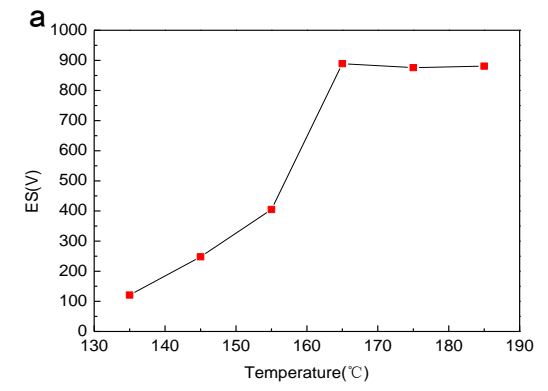

Fig. 4. Emulsion-breakage voltage subsequent to emulsifier in emulsion (oil-water ratio $=85: 15$ ) with temperature. (emulsifier concentration was $2 \mathrm{wt} \%)$.

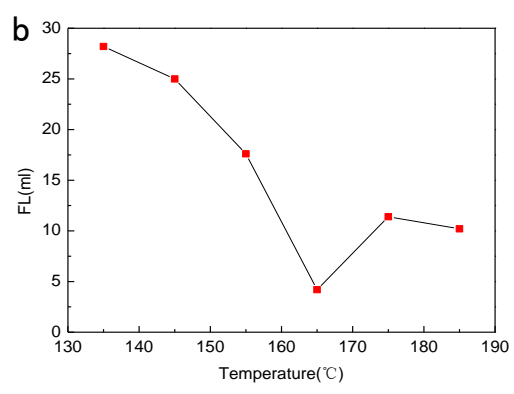

Fig. 5. The filtration subsequent to emulsifier in emulsion (oil-water ratio $=85: 15$ ) with temperature; (emulsifier concentration was $2 \mathrm{wt} \%$ ).

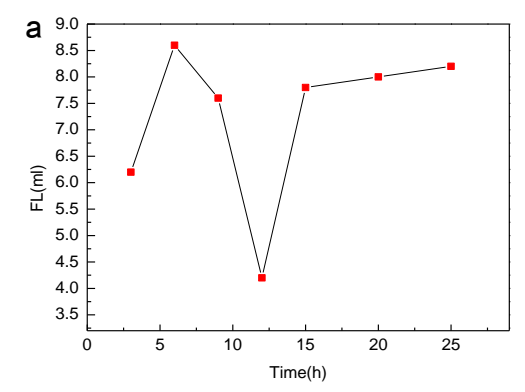

Fig. 6. The filtration subsequent to emulsifier in emulsion (oil-water ratio $=85: 15$ ) with time. (emulsifier concentration was $2 \mathrm{wt} \%$ ). 


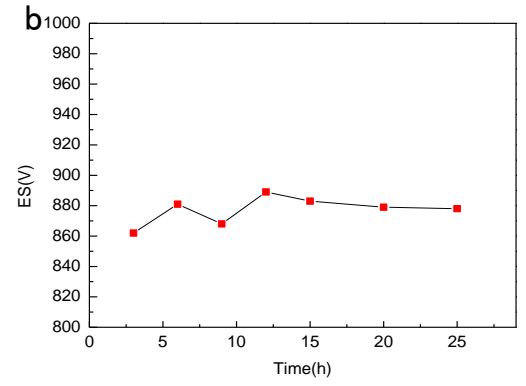

Fig. 7. Emulsion-breakage voltage subsequent to emulsifier in emulsion (oil-water ratio=85:15) with time; (emulsifier concentration was $2 \mathrm{wt} \%$ ).

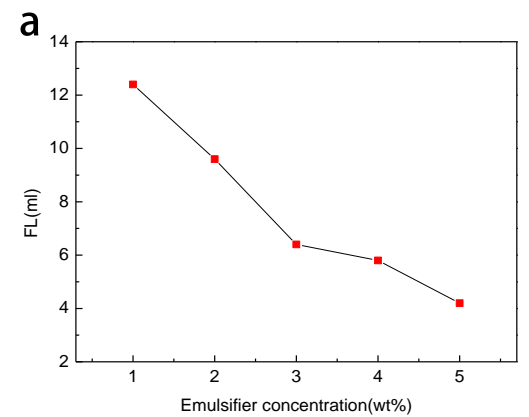

Fig. 8. Change of filtration volumes subsequent to emulsifier in emulsion (oil-water ratio=85:15) with the concentration subsequent to emulsifier.

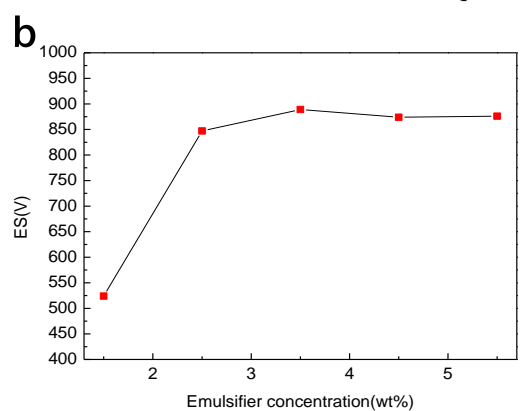

Fig. 9. Change of emulsion-breakage voltage subsequent to emulsifier in emulsion (oil-water ratio $=85: 15$ ) with the concentration subsequent to emulsifier.

a

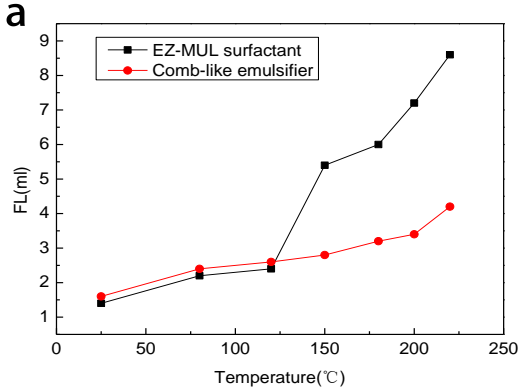

Fig. 10. Change of filtration volumes with temperature, black is EZ-MUL surfactant and red is comb-like emulsifier.

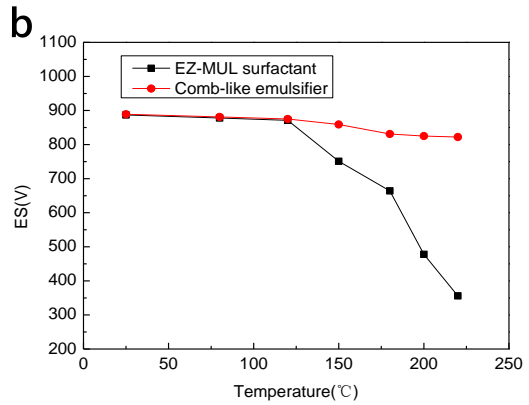

Fig. 11. Change of emulsion-breakage voltage with temperature, black is EZ-MUL surfactant and red is comb-like emulsifier.

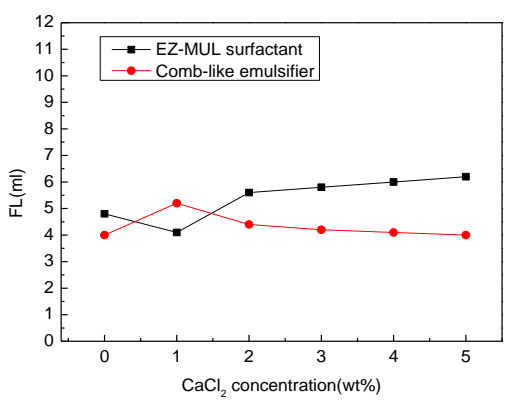

Fig. 12. Change of filtration volumes with $\mathrm{CaCl}_{2}$ concentration, black is EZ-MUL surfactant and red is comb-like emulsifier.

a

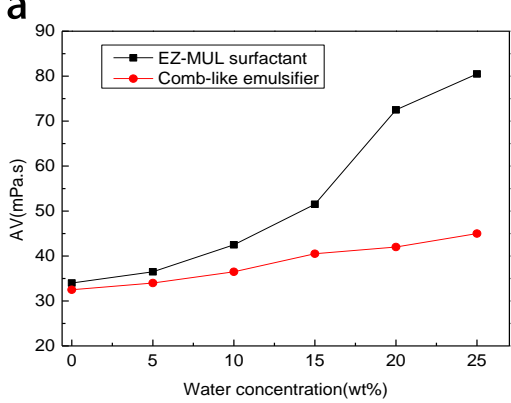

Fig. 13. Change of apparent viscosity with water concentration, black is EZ-MUL surfactant and red is comb-like emulsifier.

b

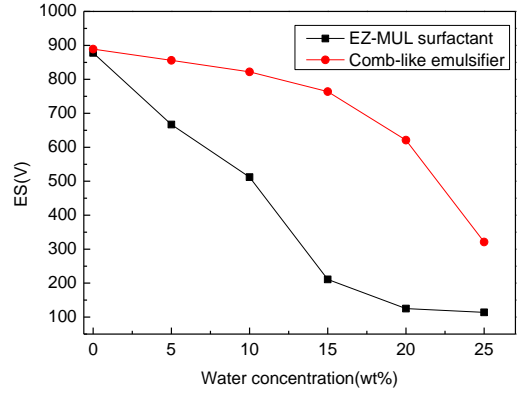

Fig. 14. Change of emulsion-breakage voltage with water concentration, black is EZ-MUL surfactant and red is comb-like emulsifier.

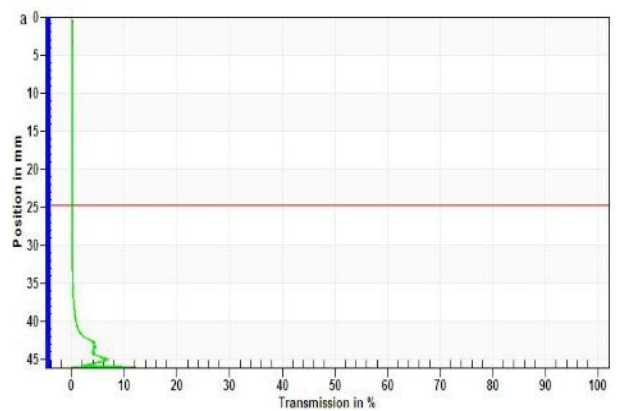

Fig. 15. Change of position subsequent to EZ-MUL surfactant in emulsion (oil-water ratio=80:20) with transmission. (emulsifier concentration was $2 \mathrm{wt} \%$ ).

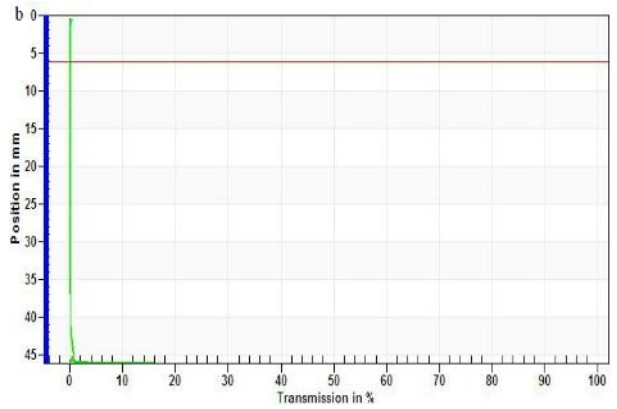

Fig. 16. Change of position subsequent to comb-like emulsifier in emulsion (oil-water ratio $=80: 20$ ) with transmission; (emulsifier concentration was $2 \mathrm{wt} \%$ ) 


\section{Mechanism Analysis}

Gemini surfactant has higher surface activity than Single molecule surfactant and its critical-micelle-concentration is one percent of the original. Comparing with Gemini surfactant, comb-like emulsifier has more hydrophobic chain which became characterized by effect of surface tension. Hence comb-like was more and more taken seriously in oil filed (Fig. 17). Bridging groups has important effect on activity of comb-like surfactant. Normally, with well flexibility and strong hydrophilicity and appropriate bending on the interface for bridging groups, culminating in packing tighter and lowering interface tension for comb-like emulsifier. Furthermore, comb-like emulsifier has eminent synergistic effect when employed with other surfactants.

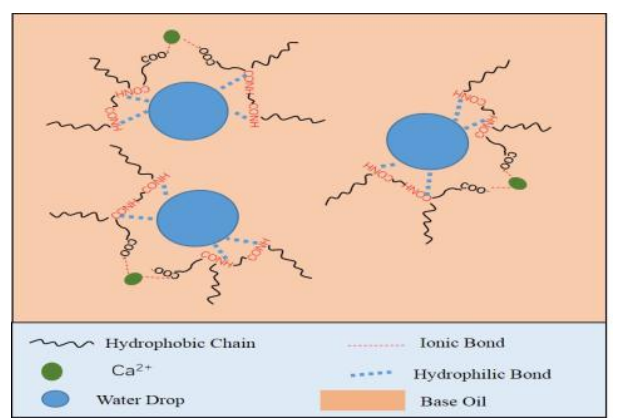

Fig. 17. Schematic diagram of the comb-like emulsifier mechanisms.

\section{CONCLUSION}

In summary, we optimized synthesis conditions based on emulsion breakage-voltage and filtration volumes of $2 \mathrm{wt} \%$ comb-like emulsifier in water-in-oil emulsion fluids. In optimal synthesis condition we characterized the structure of comb-like emulsifier became by FT-IR. The results showed that the emulsion properties of condensation polymer were characterized by separation stability tests and electric stability tests. Then the resistance properties of synthesized emulsifier to salinity, calcium and water were studied. The prepared emulsifier also has excellent rheological and filtration properties under complex conditions. The interaction mechanism of comb-like emulsifier was studied, and the results showed comb-like emulsifier with well flexibility and strong hydrophilicity and appropriate bending on the interface for bridging groups has eminent emulsion ability. Furthermore, it was shown that the comb-like emulsifier has eminent synergistic effect when employed with other surfactants. The evaluation methods for emulsion property and synthesis of comb-like emulsifier were two key factors. The next work is in progress.

\section{ACKNOWLEDGMENT}

We would like to thank for the financial support from Foundation for Innovative Research Groups of the Natural Science Foundation of China (51221003), National 863 Foundation of China (2013AA064803) for this work.

\section{REFERENCES}

[1] S. C. Magalhães, L.A. Calçada, C. M. Scheid, H. Almeida, and A. T. A. Waldmann, "Improving drilling performance with continuous online measurements of electrical stability and conductivity in oil based drilling fluids," Journal of Petroleum Science and Engineering, vol.146, no. 2, pp. 369-379, Oct. 2016.

[2] J. Hermoso, F. Martinez-Boza, and C. Gallegos, "Influence of viscosity modifier nature and concentration on the viscous flow behaviour of oil-based drilling fluids at high pressure," Applied Clay Science, vol. 87, no. 5, pp. 14-21, Jan. 2014.

[3] T. Nguyen, M. Stefan, Y. Mengjiao, T. K. Nicholas, A. Ramadan, S. Arild, and M. Jason, "Experimental study of dynamic barite sag in oil-based drilling fluids using a modified rotational viscometer and a flow loop," Journal of Petroleum Science and Engineering, vol. 78, no. 1, pp. 160-165, July 2011.

[4] M. Riley, S. Young, E. Stamatakis, and J. Quan, "Wellbore stability in unconventional shales - The design of a nano-particle fluid," Society of Petroleum Engineers, vol.10, no. 3, pp. 41-49, March 2012.

[5] J. M. Davison, M. Jones, C. E. Shuchart, and C. Gerard, "Oil-based muds for reservoir drilling: Their performance and cleanup characteristics," Society of Petroleum Engineers, vol. 4, no. 2, pp. 70-81, Jan. 2000.

[6] N. R. Kim, P. R. Ribeiro, and P. A. Pessôa-Filho, "PVT behavior of methane and ester-based drilling emulsions," Journal of Petroleum Science and Engineering, vol. 135, pp. 360-366, Nov. 2015.

[7] K. Bhola, R. J. Paswan, S. Sunil, M. Vikas, and V. P. Sharma, "Development of Jatropha oil-in-water emulsion drilling mud system," Journal of Petroleum Science and Engineering, vol. 144, pp. 10-18, Aug. 2016.

[8] G. Quercia, R. Belisario, and R. Rengifo, "Reduction of erosion rate by particle size distribution (PSD) modification of hematite as weighting agent for oil based drilling fluids," Wear, vol. 266, issues 11-12, pp. 1229-1236, May 2009

[9] Y. Lijun, K. Yili, C. Zhangxin, C. Qiang, and Y. Bin, "Wellbore instability in shale gas wells drilled by oil-based fluids," International Journal of Rock Mechanics and Mining Sciences, vol. 72, pp. 294-299, Dec. 2014.

[10] J. Yang, J. Szabo, R. E. Osgouei, J. Arensdorf, R. Swartwout, A. Hartmann, and S. A. Morris, "LWD resistivity imaging in invert emulsion oil-based drilling fluid," Unconventional Resources Technology Conference, vol.45, pp. 229-238, Aug. 2016.

[11] S. Xie, H. Deng, R. Wang, Y. Yue, B. Wu, G. Liu, and Y. Xu, "Useful recycling and safe disposal technology of waste oil based drilling fluids and its application," in Proc. International Petroleum Technology Conference, vol. 21, pp. 245-654, March 2013.

[12] J. Xiao, H. A. Nasr-El-Din, and M. Al-Bagoury, "Evaluation of ilmenite as a weighting material in oil-based drilling fluids for HPHT applications," Society of Petroleum Engineers, vol. 5, pp. 142-152, June 2013.

[13] K. Bhola and Paswan, "Development of Jatropha oil-in-water emulsion drilling mud system," Journal of Petroleum Science and Engineering, vol. 144, pp. 10-18, July 2016.

[14] A. S. Apaleke, A. Al-Majed, and M. E. Hossain, "Drilling fluid: State of the art and future trend," North Africa Technical Conference and Exhibition, vol. 3, pp. 205-217, Feb. 2012.

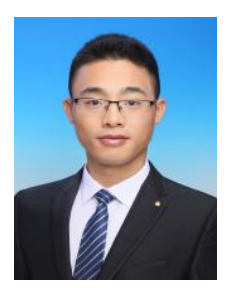

Zhengqiang Deng was born in Hunan Province, China. He got his Bachelor's degree in the Petroleum Engineering Department of Yangtze University, major in petroleum engineering in 2013. He got his master's degree in the Petroleum Engineering Department of China University of Petroleum, major in petroleum engineering in 2016. Now he is a PhD student majoring in oilfield chemistry.

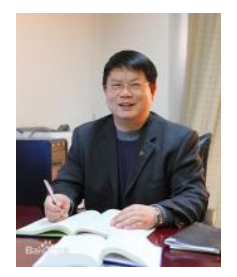

Guancheng Jiang was born in Dazu Sichuan Province, China. He got his Bachelor's degree in Chemistry Engineering Department of Xinan University of Petroleum, major in practical chemistry engineering in 1987. He got his master's degree in Chemistry Engineering Department of China University of Petroleum (Huadong), major in practical chemistry engineering in 1993. And he got his $\mathrm{PhD}$ degree in Chemistry Engineering Department of China University of Ocean (Huadong), major in practical chemistry engineering in 2005. Now he is a full professor majoring in petroleum chemistry in China university of Petroleum (Beijing). 


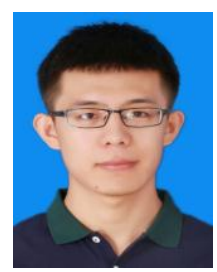

Yinbo He was born in Inner Mongolia Province, China He got his bachelor's degree in chemical engineering from Department of Nanjing University of Science and Technology, with his major in polymer science and engineering in 2011. He got his master's degree in Petroleum Engineering Department of China University of Petroleum, major in petroleum engineering in 2015 . Now he is a $\mathrm{PhD}$ student major in oilfield chemistry.

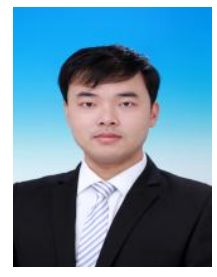

Xianbin Huang was born in Liaocheng, Shandong province, China in January, 1988, who is now a $\mathrm{PhD}$ candidate in China University of Petroleum (Beijing). $\mathrm{He}$ majored in drilling engineering and got his master degree of engineering in China University of Petroleum (Beijing) in 2013. He majored in petroleum engineering and got his Bachelor degree of Engineering in China University of Petroleum (East China) in 2010.

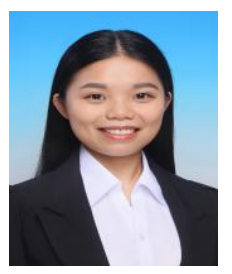

Li Wu was born in Yiyang Changsha Province, China. She got his bachelor's degree in petroleum engineering from the Department of Xinan University of Petroleum, with her major in polymer petroleum engineering in 2013. She got his master's degree in petroleum engineering from Department of China University of Petroleum, with her major in petroleum engineering in 2016. Now she is an engineer in Zhonghaiwobang Energy Investment Company. 